\title{
Correction of broadband snow albedo measurements affected by unknown slope and sensor tilts
}

\author{
Ursula Weiser ${ }^{1}$, Marc Olefs ${ }^{1}$, Wolfgang Schöner ${ }^{2}$, Gernot Weyss ${ }^{1}$, and Bernhard Hynek ${ }^{1}$ \\ ${ }^{1}$ Central Institute for Meteorology and Geodynamics (ZAMG), Vienna, Austria \\ ${ }^{2}$ Institute of Geography and Regional Research, University of Graz, Graz, Austria \\ Correspondence to: U. Weiser (ursula.weiser@zamg.ac.at)
}

Received: 16 February 2015 - Published in The Cryosphere Discuss.: 7 May 2015

Revised: 31 October 2015 - Accepted: 11 March 2016 - Published: 6 April 2016

\begin{abstract}
Geometric effects induced by the underlying terrain slope or by tilt errors of the radiation sensors lead to an erroneous measurement of snow or ice albedo. Consequently, artificial diurnal albedo variations in the order of 1-20\% are observed. The present paper proposes a general method to correct tilt errors of albedo measurements in cases where tilts of both the sensors and the slopes are not accurately measured or known. We demonstrate that atmospheric parameters for this correction model can either be taken from a nearby well-maintained and horizontally levelled measurement of global radiation or alternatively from a solar radiation model. In a next step the model is fitted to the measured data to determine tilts and directions of sensors and the underlying terrain slope. This then allows us to correct the measured albedo, the radiative balance and the energy balance. Depending on the direction of the slope and the sensors a comparison between measured and corrected albedo values reveals obvious over- or underestimations of albedo. It is also demonstrated that differences between measured and corrected albedo are generally highest for large solar zenith angles.
\end{abstract}

\section{Introduction}

The energy balance of snow and ice surfaces is strongly determined by its short-wave surface reflectivity (albedo). Once the underlying snow/ice is isothermal, the surface energy balance of a seasonal snow cover or glacier defines the amount of energy available for melt (Warren and Wiscombe, 1980).
Depending on their directions, tilted radiation sensors and terrain slopes alter albedo measurements. Most measurement sites on glaciers or seasonal snow fields are operated in remote areas, making it difficult to perform regular manual reference measurements of sensor and slope tilts. Moreover, the underlying terrain slope may change due to differential melt or changing glacial morphology and ice dynamics, also tilting the radiation sensors within periods of days or weeks and altering the direction of these tilts. This means that the geometry of the measurement site is unknown and changes with time. The use of a dual axis inclinometer to automatically determine the sensor tilts and directions is only possible if the azimuthal direction of the (tilted) radiation sensors were constant with time, which is unfortunately not the case.

Many previous studies note that tilt errors in albedo measurements can more than double with low sun elevation, especially on snow and glacier surfaces. Large deviations from the expected true diurnal variations of albedo occur due to non-horizontally levelled sensors.

In a paper investigating spectral reflected radiation on glacier surfaces, Dirmhirn and Eaton (1975) mention tilt errors of albedo measurements which lead to under- and overestimations caused by specular reflections of melting and refreezing snow and glacier surfaces depending on the incident angle of direct incoming radiation. Furthermore, they concluded that incoming short-wave radiation dominated by the direct component is underestimated at low sun angles due to the cosine response error (induced by imperfections of the glass dome of the pyranometers) and the reflection properties of the sensor's black paint, the latter is also noted by Muneer (1997), leading to an overestimation of albedo. The authors conclude that these errors can be minimised by us- 
ing instruments with a small field of view and deriving the albedo via spatial integration. Dirmhirn and Eaton (1975) also mentioned difficulties in albedo measurements over nonhorizontal surfaces and suggested eliminating this problem by using horizontal and uniform surfaces with instruments close to the ground.

Sicart et al. (2001) and Oerlemans (2010) described the same problems of albedo measurements when the glacier surface is tilted, but they assumed a horizontally levelled pyranometer and directly measured tilts and directions of the slope to correct albedo values.

Landry et al. (2007) described the influence of both a tilted slope and an inclined pyranometer on albedo measurements. They corrected the albedo values by using directly measured tilts and directions.

Ineichen et al. (1987) and Schaaf et al. (1994) described the radiation on a tilted area without snow cover, measured by an inclined pyranometer with known tilts. Measurement with a horizontally levelled pyranometer over a horizontal area served as a comparison. The results showed an apparent diurnal variation of albedo over a forest surface; even the diurnal average albedo showed differences between tilted and horizontal measurements. These results are essential because albedo of a (non-snow-covered) forest is expected to be almost constant with time, in contrast to snow albedo that changes over time due to snow metamorphism (Warren, 1982).

Allen et al. (2006) used a model of solar radiation on tilted surfaces and integrated analytically over 1 day, also considering optical properties of the atmosphere. This model was compared to measurements above surfaces with similar tilts and directions, where relative humidity, aerosols and other influences were considered. By this comparison the diffuse transmissivity was estimated as a function of the measured atmospheric parameters. Furthermore, the irradiance on tilted surfaces based on horizontal measurements was modelled. Allen et al. (2006) determined the extinction through the atmosphere in a more detailed way using measured data. In contrast to the method described in the present paper, neither a horizontal reference measurement nor a highresolution radiation model is needed to estimate atmospheric parameters.

Mannstein (1985) described a method where tilts and directions of slopes were estimated from the data of the downfacing pyranometer using the measured albedo on a preceding overcast day where snow albedo has no diurnal variation and a diurnal mean value can easily be calculated. Since Mannstein (1985) did not consider that albedo on cloudy and completely diffuse days is approximately 0.15 higher compared to clear-sky days due to the change in the spectral composition of the incoming radiation (Oerlemans, 2010), applying this method may lead to high inaccuracies.

In this paper we present a method to correct measured albedo values with unknown sensor and slope tilts that avoid the aforementioned shortcomings of existing correc- tion methods or the necessity of inclinometer measurements that are difficult to interpret or often simply are not available. The proposed correction method needs either a nearby and horizontally levelled measurement of global and diffuse solar radiation or the output of a solar radiation model to adjust some atmospheric parameters. In this way the method is transferable in space. Tilts and directions of both the terrain slope and the radiation sensors can be derived, enabling to correct measured albedo values.

A similar measurement setup as Ineichen et al. (1987) and Schaaf et al. (1994) described was made for the presented case study and the results are shown to demonstrate that albedo of a concrete surface, which should be constant, has a strong diurnal variation on clear-sky days when only the sensor is tilted.

In the present paper, Sect. 2 details the measurement setup and the derivation and workflow of the albedo correction model. In Sect. 3 we present the results of the correction method with data from one test site in Vienna, Austria, and two remote mountain sites located in the central Alpine area of Sonnblick. Section 4 discusses the shortcomings and possible improvements of the described method and Sect. 5 gives a short summary and the conclusions.

\section{Methods}

\subsection{Albedo over snow and ice surfaces}

Surface albedo $(\alpha)$, defined here as the hemispherically averaged broadband reflectance in the spectral range of $0.3-3 \mu \mathrm{m}$ (Meinander et al., 2009), is derived from incident and reflected solar radiation measured with a horizontally levelled pyranometer by dividing the values of the down-facing sensor $\left(F^{\uparrow}\right.$, reflected radiation) by those of the up-facing sensor $\left(F^{\downarrow}\right.$, global radiation):

$\alpha(t)=\frac{F^{\uparrow}(t)}{F^{\downarrow}(t)}$.

Albedo controls the net short-wave radiation flux at a snow or ice surface and thus the energy available for melt, once the underlying snow or ice is isothermal (Pellicciotti et al., 2005). Albedo is strongly dependent on snow or ice properties and atmospheric conditions, it can vary over a large range from $\alpha<0.1$ for dirty glacier ice to $\alpha>0.9$ for fresh snow (Röthlisberger, 1987; Paterson, 1994). While the albedo of pure snow for constant illumination conditions depends only on the effective grain size of the surface snow layers (Warren and Wiscombe, 1980; Wiscombe and Warren, 1980), the albedo of glacier ice is still less well understood and is a function of light scattering by bubbles and cracks (Mellor, 1977). Due to its grain size dependence, daily average snow albedo is expected to decrease in periods without snowfall due to metamorphism of the snow microstructure induced by temperature changes, melting and refreezing 
Table 1. Geographic latitude $\phi$, longitude $\theta$, altitude above sea level, tilts and aspects of the used measurement sites.

\begin{tabular}{lllll}
\hline & SBO & FLK & GOK & WHW \\
\hline$\phi$ & $12^{\circ} 57^{\prime} 28^{\prime \prime}$ & $12^{\circ} 56^{\prime} 42^{\prime \prime}$ & $12^{\circ} 57^{\prime} 50^{\prime \prime}$ & $16^{\circ} 21^{\prime} 23^{\prime \prime}$ \\
$\theta$ & $47^{\circ} 3^{\prime} 14^{\prime \prime}$ & $47^{\circ} 3^{\prime} 15^{\prime \prime}$ & $47^{\circ} 2^{\prime} 38^{\prime \prime}$ & $48^{\circ} 14^{\prime} 55^{\prime \prime}$ \\
(m a.s.1.) & 3111 & 2829 & 2678 & 198 \\
Tilt & & $8-12^{\circ}$ & $11-15^{\circ}$ & \\
Aspect & & SW & NE & \\
\hline
\end{tabular}

processes (Dirmhirn and Eaton, 1975). Generally, albedo increases with increasing solar zenith angle $\left(\vartheta_{\mathrm{s}}\right)$ due to a higher probability of the photons to be redirected out of the snow cover and due to forward scattering which is enhanced by diurnal freeze-melt cycles (Warren, 1982). This implies a strong diurnal variation of albedo during clear-sky days (Oerlemans, 2010). It is, however, generally accepted that albedo is largely independent of the solar zenith angle (SZA) for $\vartheta_{\mathrm{s}}<50^{\circ}$ (Warren and Wiscombe, 1980; Wiscombe and Warren, 1980; Konzelmann, 1995; Brock et al., 2000). In contrast, there is no diurnal variation of albedo on cloudy days that are dominated by diffuse solar radiation, and it is thus reasonable to approximate albedo by a daily average value assuming no metamorphic changes of the snow surface microstructure during the day (Pirazzini, 2004). Albedo is also known to increase with cloud cover due to spectral variations (Brock, 2004; Carroll and Fitch, 1981; Jonsell et al., 2003; Cutler and Munro, 1996; Oerlemans and Knap, 1998). As has been noted by Warren and Wiscombe (1980) and Wiscombe and Warren (1980), the responses of all commercial pyranometers deviate from a proper "cosine law" making them usually less sensitive at large incident zenith angles. When not corrected, this causes albedos at low sun elevations to be overestimated (see Eq. (1); Liljequist, 1956; Dirmhirn and Eaton, 1975). The surface geometry of a snow cover changes continuously and the tilts of the sensors increase over time, due to glacier movements caused by melting processes and ablation, snow metamorphism and the fact that the automatic weather stations (AWSs), which are used for these methods, are drilled into the glacier. Hence, it makes sense to manually adjust tilts and directions on a daily basis.

\subsection{Albedo measurements}

The albedo correction method depends on the accuracy of the used instruments and the measurement setup, which are detailed in the following paragraphes.

Albedo measurements are conducted with two opposing pyranometers (also called an albedometer), one facing the upper hemisphere measuring the incoming radiation $F^{\downarrow}$ and the other one facing the lower hemisphere measuring the reflected radiation $F^{\uparrow}$.

A pyranometer consists of a thermopile with black coating, absorbing the total solar radiation. The sensors have a glass cover that is transparent defining the exact spectral range and to protect the sensing elements. Radiation is absorbed in the thermopile, producing a voltage output by differential heating.

The used sensors are Kipp \& Zonen CNR4 net radiometers measuring all four radiation components (incoming shortwave radiation $\mathrm{SW}_{\text {in }}$, reflected short-wave radiation $\mathrm{SW}_{\text {out }}$, incoming long-wave radiation $\mathrm{LW}_{\text {in }}$, emitted long-wave radiation $\mathrm{LW}_{\text {out }}$ ) using separate sensors within the same housing, so all radiation sensors exhibit the same tilt. The expanded ( $95 \%$ level) calibration uncertainties given by the calibration certificate are given as $3.4 \%$ for the pyranometers and $6.1 \%$ for the pyrgeometers. The CNR4 has a field of view of $160^{\circ}$ and the cosine error is given as $<5 \%$ by the manufacturer (Kipp and Zonen Manual, 2010).

The net radiometers are part of the AWS on the two Sonnblick glaciers Goldbergkees (GOK) and Kleinfleißkees (FLK) (Fig. 1 and Table 1), also measuring air temperature, wind speed and direction, relative humidity and air pressure, at a height between 1.5 and $3 \mathrm{~m}$ depending on the snow depth, to determine mass and energy balance of the glaciers. A solar panel and battery serve as the power supply for all used sensors. The AWSs are drilled into the glacier ice and are located in a remote area where shadows from the surrounding mountains are minimal and the down-facing pyranometer only sees the glacier surface without any nearby mountains.

A MEAS DQG-Series conductometric dual axis inclinometer is attached to each AWS. Four oppositely polarised electrodes are dipped into an electrolytic fluid, producing a voltage that is measured (Amsys, 2012). The conductivity of the electrolyte depends on its depth. When the sensor is tilted, the depth of the electrolyte and consequently its conductivity changes. The uncertainty of the inclinometer given by the manufacturer is $0.5 \%$ within a temperature range of $-40^{\circ} \mathrm{C}<\mathrm{T}<85^{\circ} \mathrm{C}$. To use the data of the inclinometer it is necessary to know the orientation of one axis (e. g. southwards). The orientation of the AWS on the glacier changes continuously due to glacier dynamics and snow metamorphism and is therefore estimated with an uncertainty of $\pm 5 \%$ since the sensor is fixed to the AWS support hardware.

All radiation data of the AWSs were stored with a resolution of $1 \mathrm{~min}$, all other values with 10 and $60 \mathrm{~min}$ average output. For the used method 1 min data of short-wave radiation of the pyranometers connected to each AWS are used and compared to 1 min average data of the Suntracker. 


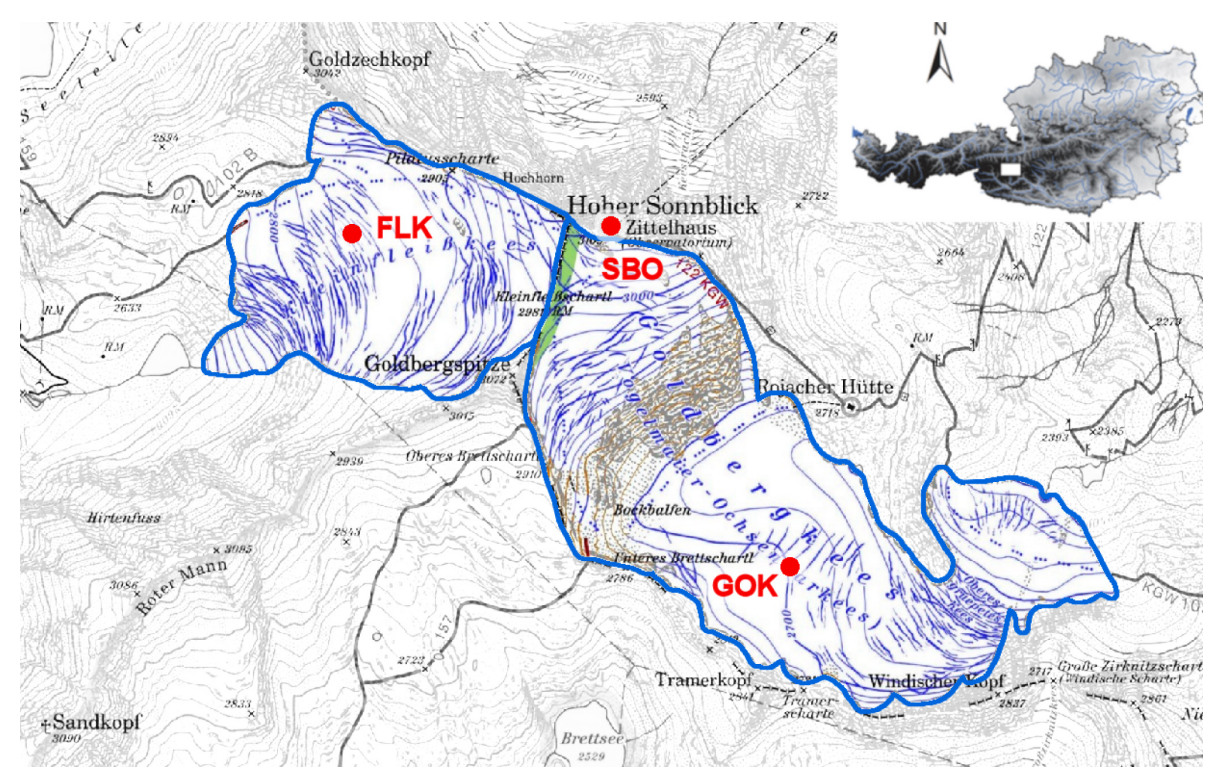

Figure 1. Map of Sonnblick area (taken from Alpenvereinskarten digital 2007, v. 2.0.9.0, DAV, Munich; ÖAV, Innsbruck). The red marks indicate the positions of the AWSs and SBO.

\subsection{Solar radiation reference data}

Additionally, high-quality solar radiation reference measurements from a nearby Suntracker are used. The latter is part of the Austrian radiation monitoring network (ARAD) and the Baseline Surface Radiation Network (BSRN) to advance national climate monitoring and to support satellite retrieval, modelling and solar energy development. The measurement setup and a detailed uncertainty estimate is shown in Olefs et al. (2015). The Suntracker is equipped with two pyranometer and one pyrgeometer next to each other with a field of view of $180^{\circ}$. The tracker follows the sun to shadow one of the pyranometers in order to measure global and diffuse radiation.

To make the albedo correction method more transferable in space, a solar radiation model can be used instead of the nearby reference radiation data. We used the STRAHLGRID model (Olefs et al., 2013; Olefs and Schöner, 2012), a parametric solar radiation model. In STRAHLGRID, direct and diffuse solar radiation is calculated considering atmospheric turbidity, cloudiness effects for direct and diffuse radiation and terrain effects (shading, terrain and multiple reflections). Usually, the model is driven with gridded meteorological data from the Integrated Nowcasting through Comprehensive Analysis (INCA) system (Haiden et al., 2011) at 100 $\mathrm{m}$ spatial and $15 \mathrm{~min}$ temporal resolution. In the present case the model estimated solar irradiance for the location of each AWS in clear-sky mode (no cloudiness) using daily MODIS aerosol optical depth (AOD) and hourly INCA integrated water vapour data as input for aerosol and water vapour transmittances calculated in the model.
Figure 1 and Table 1 show the location and some details about the measurement stations: Suntracker on Sonnblick Observatory (SBO), AWS FLK, AWS GOK and Central Institute for Meteorology and Geodynamics (ZAMG) in Vienna (WHW).

In order to test the albedo correction method we installed a measurement setup on the roof of ZAMG (WHW), over a concrete surface. This experiment was performed to prove that even a constant albedo changes with a tilted sensor and has to be corrected to get realistic albedo ranges, as demonstrated in Fig. 2 (right). To determine the exact and presumably constant albedo of the concrete, the pyranometer was first levelled horizontally (Fig. 2, left). In the literature, albedo over a concrete surface is given by $\alpha_{\text {concrete }}=0.17$ 0.27 (Santamouris, 2006).

\subsection{Model for solar radiation on a tilted surface}

\subsubsection{Radiation model for a horizontal plane}

The used model is first demonstrated for the direct solar radiation on a horizontal plane. For this method, which uses the solar position algorithm (SPA) (Reda and Andreas, 2008) to calculate the solar radiation on top of the atmosphere (TOA), the general form of the Lambertian cosine law is used:

$\mathrm{d} F=F \cdot \cos \vartheta_{\mathrm{s}} \cdot \mathrm{d} \omega$,

where $F$ is the irradiance of the incoming radiation, which is determined by the radiant flux per unit area, $\vartheta_{\mathrm{s}}$ the SZA and $\omega$ the solid angle of the sun as seen from the unit area. The irradiance per unit area on TOA is called solar constant, assumed here as $S=1367 \mathrm{~W} \mathrm{~m}^{-2}$ (Corripio, 2002). 

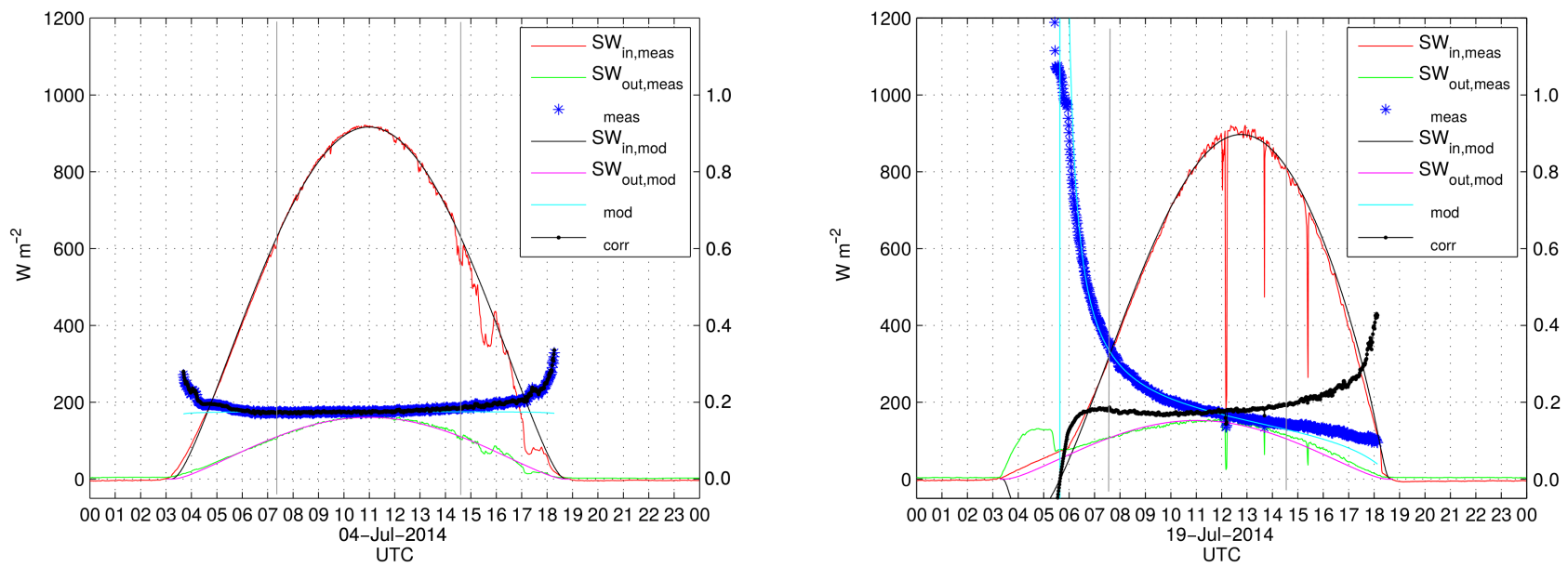

Figure 2. Measured, modelled and corrected $\mathrm{SW}_{\mathrm{in}}, \mathrm{SW}_{\text {out }}$ and $\alpha$ with a horizontally levelled (left) and an intentionally inclined pyranometer (right) at WHW for 2 days in July 2014.

The near-surface incoming direct solar radiation on a horizontal plane $\left(F_{\text {hor }}\right)$ is given by

$F_{\text {hor }}=S_{\text {terr }} \cdot \cos \vartheta_{\mathrm{s}}$,

where $S_{\text {terr }}$ is the near-surface, normal incidence direct solar radiation.

Solar radiation is weakened by absorption and scattering between TOA and the surface. This process for clear-sky days can be described by the Beer-Lambert-Bouguer law (Rontu Carlon et al., 2010), which uses the extinction coefficient $\widetilde{\varepsilon}$ and $\varepsilon$ respectively, depending on the condition of the atmosphere (e.g. aerosols and water vapour content):

$I=I_{0} e^{-\widetilde{\varepsilon} d}=I_{0} e^{-\frac{\varepsilon}{\cos \vartheta_{s}}}$

where $I$ and $I_{0}$ are the intensities of the near-surface global and TOA incident solar radiation respectively and $d$ is the optical path length in the atmosphere.

To increase the accuracy of the developed model, a linear factor $V$ is introduced to account for the limited spectral range of the instrument $(0.3-2.8 \mu \mathrm{m})$ (Kipp and Zonen Manual, 2010) compared to the extra terrestrial solar radiation or solar constant (Corripio, 2002). Using Eq. (4) $S_{\text {terr }}$ can be written as

$S_{\text {terr }}=\frac{S}{\widetilde{r}^{2}} \cdot V \cdot e^{-\varepsilon \frac{1}{\cos \vartheta_{s}}}$

where $\widetilde{r}$ is the ratio of the actual and the mean sun-earth distance. $\varepsilon$ and $V$ are two unknown parameters which have to be determined in the first iteration of the correction.

Conclusively, in this model the near-surface incoming direct solar irradiance on a horizontal plane can be expressed from Eqs. (3) and (5) as

$F_{\text {hor }}=\frac{S}{\widetilde{r}^{2}} \cdot V \cdot e^{-\varepsilon \frac{1}{\cos \vartheta_{\mathrm{s}}}} \cdot \cos \vartheta_{\mathrm{s}}$.

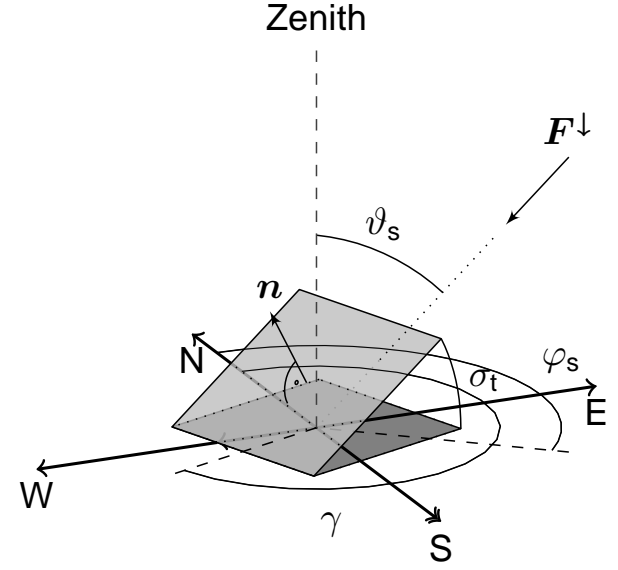

Figure 3. Geometric account of a tilted surface.

\subsubsection{Radiation model for a tilted plane}

As glacier surfaces are located in complex terrain, most glaciological measurements are conducted on tilted surfaces as shown in Fig. 3. $\vartheta_{\mathrm{s}}$ in the Lambertian cosine law (Eq. 2) transforms now to $\vartheta_{\text {tilt }}$, the solar incidence angle of any tilted plane in general, and can be expressed through

$\cos \vartheta_{\text {tilt }}=\boldsymbol{F}^{\downarrow} \cdot \boldsymbol{n}=\sin \vartheta_{\mathrm{s}} \cos \varphi_{\mathrm{s}} \sin \sigma \cos \gamma$

$+\sin \vartheta_{\mathrm{s}} \sin \varphi_{\mathrm{s}} \sin \sigma \sin \gamma+\cos \vartheta_{\mathrm{s}} \cos \sigma$,

where $\boldsymbol{n}$ is the normal vector to the slope, $\varphi_{\mathrm{s}}$ the solar azimuth angle, $\sigma$ the tilt and $\gamma$ the aspect of the slope.

Consequently, the incoming direct radiation on a tilted plane can be derived from Eqs. (6) and (7) as

$F_{\text {tilt }}^{\text {dir }}=S_{\text {terr }} \cdot \cos \vartheta_{\text {tilt }}=\frac{S}{\widetilde{r}^{2}} \cdot V \cdot e^{-\varepsilon \frac{1}{\cos \vartheta_{\mathrm{s}}}}$

$\cdot\left(\sin \vartheta_{\mathrm{s}} \cos \varphi_{\mathrm{s}} \sin \sigma \cos \gamma+\sin \vartheta_{\mathrm{s}} \sin \varphi_{\mathrm{s}} \sin \sigma \sin \gamma+\cos \vartheta_{\mathrm{s}} \cos \sigma\right)$. 


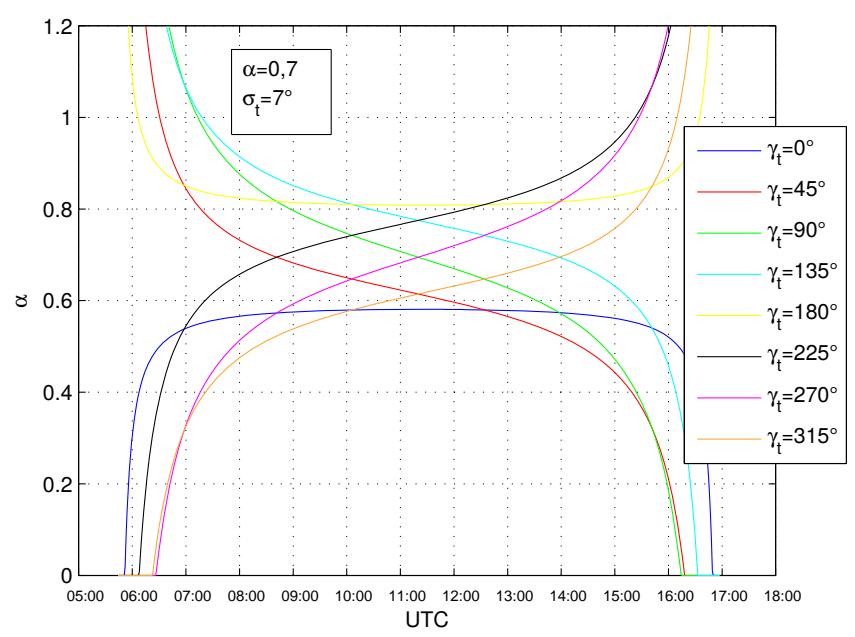

Figure 4. Diurnal variations of albedo with a constant true albedo and a constant tilt of the slope but differing aspects.

To distinguish between a tilted plane and an inclined pyranometer the indices $\sigma_{\mathrm{t}}, \gamma_{\mathrm{t}}$ for the tilted glacier surface and $\sigma_{\mathrm{p}}, \gamma_{\mathrm{p}}$ for the pyranometer are used from here on.

In an idealised model of a measuring system with exactly horizontally levelled sensors, the incoming radiation hits the pyranometer and the tilted surface and is subsequently reflected back to the upper hemisphere as a function of the true snow albedo. In this idealised case using Eq. (1) the irradiance measured with the down-facing sensor can be expressed as

$F^{\uparrow}=\alpha_{\text {true }} \cdot F_{\text {tilt }}^{\text {dir }}$,

where $F_{\text {tilt }}^{\text {dir }}$ is defined in Eq. (8) and $\alpha_{\text {true }}$ is the true value of the (still unknown) albedo. For now a hypothetical case is assumed where the total incoming radiation only consists of the direct beam and the diffuse part of the radiation is neglected and described in detail later in the text.

The reflected part of the irradiance is measured by the down-facing pyranometer, so the measured albedo can be written as

$\alpha_{\text {meas }}=\frac{F^{\uparrow}}{F^{\downarrow}}=\frac{\alpha_{\text {true }} \cdot F_{\text {tilt }}^{\text {dir }}}{F^{\downarrow}}$.

Combining Eqs. (5), (8) and (10), $\alpha_{\text {meas }}$ can be simplified to

$\alpha_{\text {meas }}=\frac{\alpha_{\text {true }} \cdot \frac{S}{\widetilde{r}^{2}} \cdot V \cdot e^{-\varepsilon \frac{1}{\cos \vartheta_{\mathrm{s}}}} \cdot \cos \vartheta_{\text {tilt }}}{\frac{S}{\widetilde{r}^{2}} \cdot V \cdot e^{-\varepsilon \frac{1}{\cos \vartheta_{\mathrm{s}}}} \cdot \cos \vartheta_{\mathrm{s}}}=\alpha_{\text {true }} \frac{\cos \vartheta_{\text {tilt }}}{\cos \vartheta_{\mathrm{s}}}$,

and the true albedo can be written as

$\alpha_{\text {true }}=\alpha_{\text {meas }} \frac{\cos \vartheta_{\mathrm{s}}}{\cos \vartheta_{\text {tilt }}}$.

In Eq. (12) it is assumed that the pyranometer is levelled horizontally and the reflection of the snow cover is isotropic, which assumes that the surface is completely flat and homogenous.

Figure 4 shows the diurnal albedo variations derived with Eq. (11), where a constant true albedo $\left(\alpha_{\text {true }}=0.7\right)$ and a constant tilted slope $\left(\sigma_{\mathrm{t}}=7^{\circ}\right)$ are modelled and only the aspect of the slope $\left(\gamma_{\mathrm{t}}\right)$ varies.

To improve the described model it has to be considered that the total incoming radiation measured by the up-facing pyranometer consists not only of a direct beam but also of a diffuse component. Consequently, the total incoming radiation can be split into a direct and a diffuse part ( $p_{\text {dir }}$ and $p_{\text {diff). }}$.

In order to simplify the model, incoming diffuse fluxes over a tilted plane are regarded to be isotropic and equal to incoming diffuse radiation on a horizontal surface. Therefore the incoming radiation on a tilted plane can be split into

$F_{\text {tilt }}=p_{\text {dir }} F_{\text {tilt }}^{\text {dir }}+p_{\text {diff }} F_{\text {hor }}$.

Thus the measured albedo is

$\alpha_{\text {meas }}=\frac{\alpha_{\text {true }}\left(F_{\text {dir }}+F_{\text {diff }}\right)}{F^{\downarrow}}$,

where

$F_{\text {dir }}=\frac{S}{\widetilde{r}^{2}} \cdot V \cdot e^{-\varepsilon \frac{1}{\cos \vartheta_{\mathrm{s}}}} \cdot p_{\text {dir }} \cos \vartheta_{\text {tilt }}$,

and

$F_{\text {diff }}=\frac{S}{\widetilde{r}^{2}} \cdot V \cdot e^{-\varepsilon \frac{1}{\cos \vartheta_{\mathrm{s}}}} \cdot p_{\text {diff }} \cos \vartheta_{\mathrm{s}}$.

The total incoming irradiance can be derived by inserting Eqs. (15) and (16) into Eq. (12), using Eq. (14), and, finally, the true albedo can be written as

$\alpha_{\text {true }}=\alpha_{\text {meas }} \frac{\cos \vartheta_{\mathrm{s}}}{p_{\text {dir }} \cos \vartheta_{\text {tilt }}+p_{\text {diff }} \cos \vartheta_{\mathrm{s}}}$.

Eq. (17) assumes a constant azimuth angle of $\vartheta_{\text {tilt }}$ (facing south).

\subsubsection{Radiation model for a tilted slope with an inclined sensor}

In practise, pyranometers are not exactly horizontally levelled. The incoming radiation hits the inclined up-facing pyranometer and the tilted surface, from where it is reflected in an isotropic way into the inclined down-facing pyranometer (Fig. 5). However, since we assume that the reflection is completely diffuse, the inclination of the down-facing pyranometer is assumed to be irrelevant.

The true snow albedo can now be derived, considering a tilted slope and an inclined pyranometer by using Eq. (10)

$\alpha_{\text {true }}=\alpha_{\text {meas }} \frac{F_{\text {pyr }}}{F_{\text {tilt }}}=\alpha_{\text {meas }} \frac{\cos \vartheta_{\mathrm{p}}}{\cos \vartheta_{\text {tilt }}}$, 


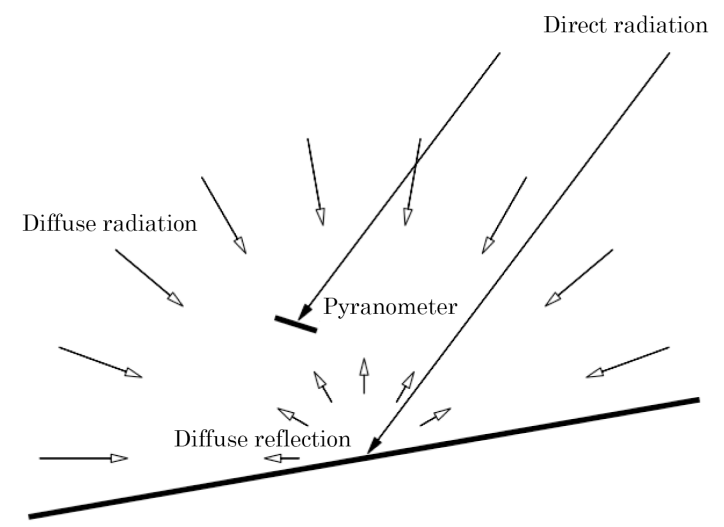

Figure 5. Isotropic reflection from a tilted slope with an inclined pyranometer.

where $\vartheta_{\mathrm{p}}$ is the inclination angle of the pyranometer and $\vartheta_{\mathrm{t}}$ the inclination angle of the slope, both inclination angles derived as in Eq. (7), $F_{\text {pyr }}$ is the incoming irradiance perpendicular to the up-facing pyranometer and $F_{\text {tilt }}$ the irradiance hitting the slope.

Figure 6 shows the calculated diurnal albedo using this model with a constant diurnal true albedo $\left(\alpha_{\text {true }}=0.7\right)$ for different tilts and inclinations of slope and pyranometer derived with Eq. (18).

Taking into account the diffuse radiation, $F_{\mathrm{pyr}}$ and $F_{\text {tilt }}$ have to be split into a direct and a diffuse part analogously to Eqs. (15) and (16). $\cos \vartheta_{\mathrm{p}}$ and $\cos \vartheta_{\mathrm{t}}$ can be derived with tilts and directions of sensor and slope analogously to Eq. (7):

$$
\begin{aligned}
& \cos \vartheta_{\mathrm{p}}=\boldsymbol{F}^{\downarrow} \cdot \boldsymbol{n}=\sin \vartheta_{\mathrm{s}} \cos \varphi_{\mathrm{s}} \sin \sigma_{\mathrm{p}} \cos \gamma_{\mathrm{p}} \\
& +\sin \vartheta_{\mathrm{s}} \sin \varphi_{\mathrm{s}} \sin \sigma_{\mathrm{p}} \sin \gamma_{\mathrm{p}}+\cos \vartheta_{\mathrm{s}} \cos \sigma_{\mathrm{p}}, \\
& \cos \vartheta_{\mathrm{t}}=\boldsymbol{F}^{\downarrow} \cdot \boldsymbol{n}=\sin \vartheta_{\mathrm{s}} \cos \varphi_{\mathrm{s}} \sin \sigma_{\mathrm{t}} \cos \gamma_{\mathrm{t}} \\
& +\sin \vartheta_{\mathrm{s}} \sin \varphi_{\mathrm{s}} \sin \sigma_{\mathrm{t}} \sin \gamma_{\mathrm{t}}+\cos \vartheta_{\mathrm{s}} \cos \sigma_{\mathrm{t}} .
\end{aligned}
$$

Considering these assumptions, the true albedo can be expressed using the measured albedo $\alpha_{\text {meas }}$, the direct $p_{\text {dir }}$ and the diffuse part $p_{\text {diff }}$ of the incoming radiation, the solar zenith angle $\vartheta_{\mathrm{s}}$ and the tilts of the slope $\vartheta_{\mathrm{t}}$ and the sensor $\vartheta_{\mathrm{p}}$ :

$\alpha_{\text {true }}=\alpha_{\text {meas }}\left(\frac{p_{\text {diff }} \cdot \cos \vartheta_{\mathrm{s}}+p_{\text {dir }} \cdot \cos \vartheta_{\mathrm{p}}}{p_{\text {diff }} \cdot \cos \vartheta_{\mathrm{s}}+p_{\text {dir }} \cdot \cos \vartheta_{\mathrm{t}}}\right)$

or, using $p_{\text {dir }}+p_{\text {diff }}=1$,

$\alpha_{\text {true }}=\alpha_{\text {meas }}\left(\frac{p_{\text {diff }} \cdot \cos \vartheta_{\mathrm{s}}+\left(1-p_{\text {diff }}\right) \cdot \cos \vartheta_{p}}{p_{\text {diff }} \cdot \cos \vartheta_{\mathrm{s}}+\left(1-p_{\text {diff }}\right) \cdot \cos \vartheta_{\mathrm{t}}}\right)$.

To correct the albedo with Eq. (22) on clear-sky days, it is assumed that following parameters are constant over 1 day:

1. extinction coefficient $\varepsilon$

2. linear factor $V$
3. tilt $\sigma_{\mathrm{t}}$ and direction $\gamma_{\mathrm{t}}$ of the slope

4. tilt $\sigma_{\mathrm{p}}$ and direction $\gamma_{\mathrm{p}}$ of the pyranometer

5. diffuse part of incoming radiation $p_{\text {diff }}$.

The residuals of the results show that there is almost no diurnal variation between the measured data and the model where the extinction coefficient $\varepsilon$ and the ratio between the spectral range of the pyranometer and TOA irradiance $V$ are considered. The reason for this is that AOD has a small range of values in high altitudes (Weihs et al., 1999).

The tilts and directions of both the slope and the sensor, $\sigma_{\mathrm{t}}, \gamma_{\mathrm{t}}, \sigma_{\mathrm{p}}, \gamma_{\mathrm{p}}$, are also considered to be constant over a day, because neither the surface nor the sensor shows relevant changes within small periods. As evidence the residuals of the results are considered, which show no relevant diurnal variations.

For all evaluated clear-sky days in the Sonnblick area and in Vienna, both the measured data of the Suntracker and the STRAHLGRID model show a diurnal mean value of the diffuse part of incoming radiation of $p_{\text {diff }} \simeq 10 \%$; therefore this value can be assumed to be constant for clear-sky days.

The diffuse reflection of incoming radiation by the surface is assumed to be isotropic and constant for a day, and our analysis corrects albedo for periods within a SZA of $\vartheta_{\mathrm{s}}<50^{\circ}$ where an average value for 1 day is taken.

\subsection{Workflow to correct albedo measurements}

The detailed workflow of the albedo correction method is shown in Fig. 7 and summarised in the following subsections.

\subsubsection{Step A: derive atmospheric parameters for clear-sky days}

\section{Nearby reference measurement}

To calibrate the radiation model, the atmospheric model parameters are fitted to nearby reference radiation measurements so as to reduce the residuals between modelled and measured global radiation using the method of least squares.

\section{Solar radiation model}

Instead of reference measurements, the output of a solar radiation model can be used to derive the atmospheric parameters of the albedo correction model.

\subsubsection{Step B: inclination and direction of the pyranometer}

After the atmospheric parameters for clear-sky days are estimated, the inclinations and directions of the sensors can be derived by using Eq. (13) with Eq. (19). 


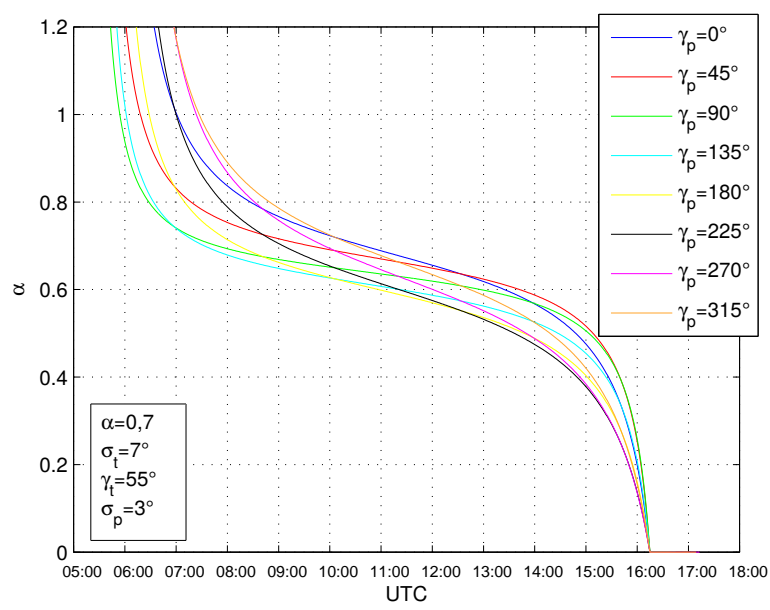

(a)

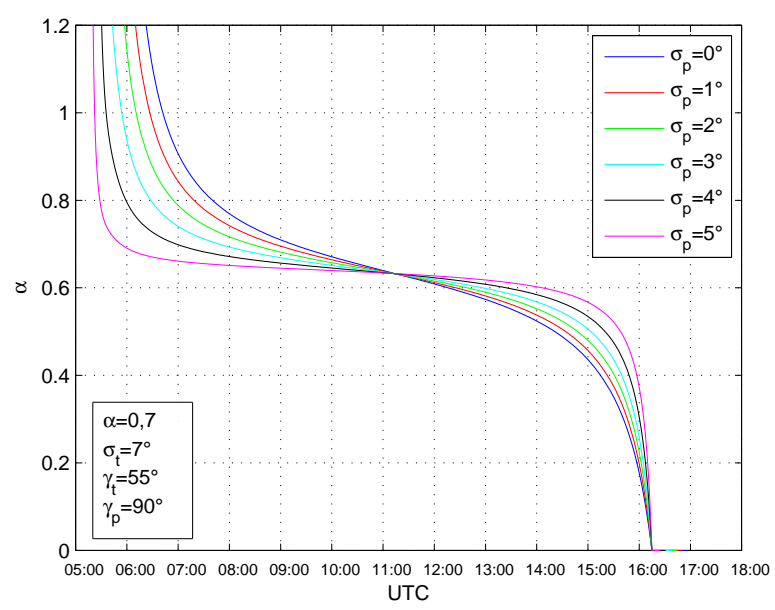

(c)

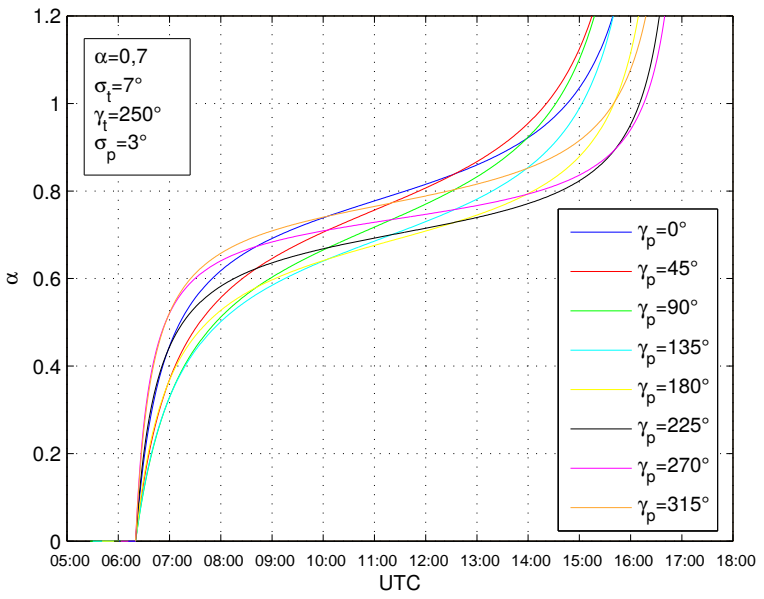

(b)

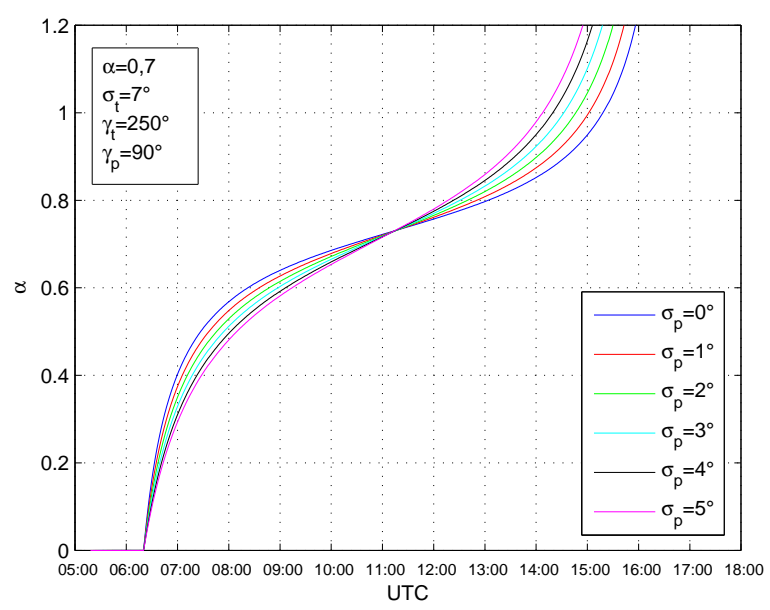

(d)

Figure 6. Calculated albedo with a constant diurnal true albedo for (a and b) differently oriented $\left(\gamma_{\mathrm{p}}\right)$ and $(\mathbf{c}$ and $\mathbf{d})$ inclined $\left(\sigma_{\mathrm{p}}\right)$ pyranometers, different tilted $\left(\sigma_{t}\right)$ and directed $\left(\gamma_{t}\right)$ slopes.

\subsubsection{Step C: tilt and direction of the slope}

The process to determine the unknown tilts and directions of the slope out of the measured reflected radiation $F^{\uparrow}$ is more complicated because $F^{\uparrow}$ also depends on the unknown albedo of the surface.

It is assumed that the incoming radiation of the slope is directly proportional to the reflected radiation measured by the down-facing pyranometer with the proportionality factor being the yet unknown albedo $\alpha_{\text {true }}$ :

$F^{\uparrow}=\alpha_{\text {true }} \cdot \cos \vartheta_{\mathrm{t}}$,

where $\vartheta_{\mathrm{t}}$ is the solar incidence angle on the slope, defined in Eq. (20) and illustrated in Fig. 3.

The task now is to find a combination of $\sigma_{\mathrm{t}}$ (tilt) and $\gamma_{\mathrm{t}}$ (direction) in such a way that the modelled incoming radiation on the tilted slope and the measured values for $F^{\uparrow}$ only differ by a factor $C$ that should be a constant value for the day in progress. First of all, for any combination of $\sigma_{\mathrm{t}}$ and $\gamma_{\mathrm{t}}$, the constant $C$ is calculated as the average over 1 day:

$C=\left\langle\left(\frac{F^{\uparrow}}{\cos \vartheta_{\mathrm{t}}}\right)\right\rangle$,

where $\cos \vartheta_{\mathrm{t}}$ is expressed in Eq. (20).

For every factor $C$, the method of least squares is used to minimise the difference between modelled and measured reflected radiation with Eq. (25):

$$
\left(C \cdot \cos \vartheta_{\mathrm{t}}-F^{\uparrow}\right)^{2} \longrightarrow \min
$$

This expression has to be minimal for the combination of $\sigma_{\mathrm{t}}$ and $\gamma_{\mathrm{t}}$, for which the proportionality factor $C$ is constant for 1 


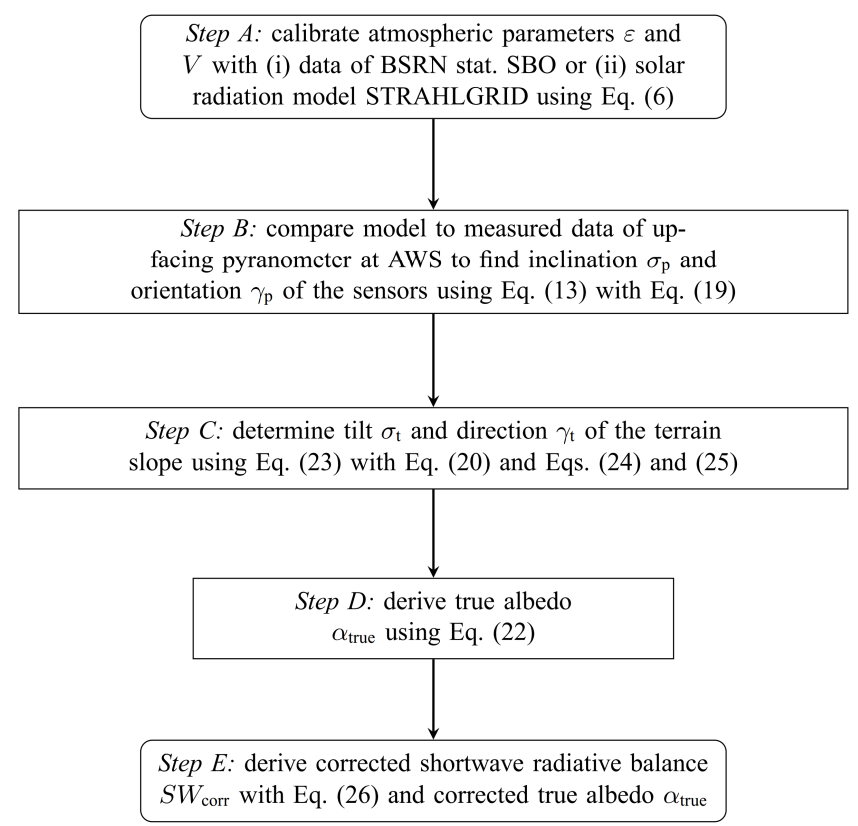

Figure 7. Workflow to correct daily albedo values.

day in an ideal case and $\sigma_{\mathrm{t}}$ and $\gamma_{\mathrm{t}}$ fit the measured data of the reflected measured radiation $F^{\uparrow}$, calculated with Eq. (23).

\subsubsection{Step D: derive true albedo}

Now that all inclinations, tilts and directions are estimated for 1 day, the true albedo can be derived from the measured data with Eq. (22).

Compared to steps $\mathrm{A}-\mathrm{C}$, where the results are determined by fitting the model to the measured values with the method of least squares, Eq. (22) is only used with measured $\left(F^{\uparrow}, F^{\downarrow}, p_{\text {diff }}\right)$ and derived $\left(\sigma_{\mathrm{p}}, \gamma_{\mathrm{p}}, \sigma_{\mathrm{t}}, \gamma_{\mathrm{t}}\right)$ parameters within a SZA of $\vartheta_{\mathrm{s}}<50^{\circ}$. The daily mean value and the standard deviation (SD) of $\alpha_{\text {true }}$ are determined.

\subsubsection{Step E: derive radiative balance}

The purpose of correcting albedo values on clear-sky days is the correction of short-wave radiative balance. The effects are shown by comparing measured and corrected radiative balance in Fig. 11.

The net short-wave radiation $\mathrm{SW}_{\text {net }}$ is derived as

$$
\begin{aligned}
\mathrm{SW}_{\text {net }} & =\mathrm{SW}_{\text {in }}+\mathrm{SW}_{\text {out }} \\
& =\mathrm{SW}_{\text {in }}(1-\alpha) .
\end{aligned}
$$

In Eq. (26) the albedo $\alpha$ can be used with both $\alpha_{\text {meas }}$ and $\alpha_{\text {corr. }}$.
Table 2. Measured and retrieved sensor inclinations and directions and daily average albedo, including all standard deviations, at WHW on 4 and 19 July 2014 on a horizontal concrete surface.

\begin{tabular}{lcc}
\hline & 4 Jul 2014 & 19 Jul 2014 \\
\hline$\varepsilon$ & $0.102 \pm 0.001$ & $0.111 \pm 0.002$ \\
$\varepsilon_{\text {mod }}$ & $0.129 \pm 0.001$ & $0.118 \pm 0.002$ \\
$V$ & $0.86 \pm 0.03$ & $0.84 \pm 0.04$ \\
$V_{\text {mod }}$ & $0.81 \pm 0.03$ & $0.80 \pm 0.04$ \\
$\sigma_{\mathrm{p}}$ & $0.3^{\circ} \pm 0.0003^{\circ}$ & $24.0^{\circ} \pm 0.024^{\circ}$ \\
$\gamma_{\mathrm{p}}$ & $5.0^{\circ} \pm 0.025^{\circ}$ & $265.0^{\circ} \pm 1.325^{\circ}$ \\
$\sigma_{\mathrm{p} \text { (meas) }}$ & $1.27^{\circ} \pm 0.01^{\circ}$ & $23.33^{\circ} \pm 0.12^{\circ}$ \\
$\gamma_{\mathrm{p} \text { (meas) }}$ & $170.44^{\circ} \pm 0.85^{\circ}$ & $264.32^{\circ} \pm 1.32^{\circ}$ \\
$\alpha_{\text {meas }}$ & $0.1791 \pm 0.0063$ & $0.2083 \pm 0.0696$ \\
$\alpha_{\text {corr }}$ & $0.1789 \pm 0.0064$ & $0.1773 \pm 0.0082$ \\
\hline
\end{tabular}

Table 3. Results of measured and corrected inclinations and directions and daily average albedo, including all standard deviations, at the AWS sites Kleinfleißkees on 5 March 2011 and Goldbergkees on 27 June 2011.

\begin{tabular}{lcc}
\hline & FLK, 5 Mar 2011 & GOK, 27 Jun 2011 \\
\hline$\varepsilon$ & $0.051 \pm 0.001$ & $0.071 \pm 0.002$ \\
$\varepsilon_{\text {mod }}$ & $0.071 \pm 0.001$ & $0.081 \pm 0.002$ \\
$V$ & $0.95 \pm 0.03$ & $0.93 \pm 0.04$ \\
$V_{\text {mod }}$ & $0.91 \pm 0.03$ & $0.90 \pm 0.04$ \\
$\sigma_{\mathrm{t}}$ & $10.57^{\circ} \pm 0.05^{\circ}$ & $13.51^{\circ} \pm 0.11^{\circ}$ \\
$\gamma_{\mathrm{t}}$ & $225.00^{\circ} \pm 5.60^{\circ}$ & $41.43^{\circ} \pm 4.93^{\circ}$ \\
$\sigma_{\mathrm{p}}$ & $4.72^{\circ} \pm 0.11^{\circ}$ & $3.93^{\circ} \pm 0.08^{\circ}$ \\
$\gamma_{\mathrm{p}}$ & $247.62^{\circ} \pm 3.37^{\circ}$ & $9.68^{\circ} \pm 0.68^{\circ}$ \\
$\sigma_{\mathrm{p} \text { (meas) }}$ & $4.29^{\circ} \pm 0.02^{\circ}$ & $7.77^{\circ} \pm 0.39^{\circ}$ \\
$\gamma_{\mathrm{p} \text { (meas })}$ & $305.43^{\circ} \pm 1.53^{\circ}$ & $52.54^{\circ} \pm 0.26^{\circ}$ \\
$\alpha_{\text {meas }}$ & $0.86 \pm 0.07$ & $0.51 \pm 0.06$ \\
$\alpha_{\text {corr }}$ & $0.75 \pm 0.01$ & $0.54 \pm 0.01$ \\
\hline
\end{tabular}

\section{Results}

\subsection{Atmospheric parameters}

\subsubsection{Nearby reference measurement}

To determine the described parameters that depend on the composition of the atmosphere, the data of the Suntracker are compared to the model of TOA for each location, in this case the roof of ZAMG in Vienna and the Sonnblick Observatory. In both cases the ranges of $\varepsilon$ and $V$ are within the same intervals, shown in Tables 2 and 3 .

The determined extinction coefficients resulting from model adaptions range between $\varepsilon=0.001$ and 0.2 , which concur well with known ranges (DeWalle and Rango, 2008), as a result of several influences, such as water vapour, aerosols and other meteorological parameters that vary continuously.

The ratio between the spectral range of the pyranometer and the irradiance on TOA ranges between $V=0.8$ and 1 , 

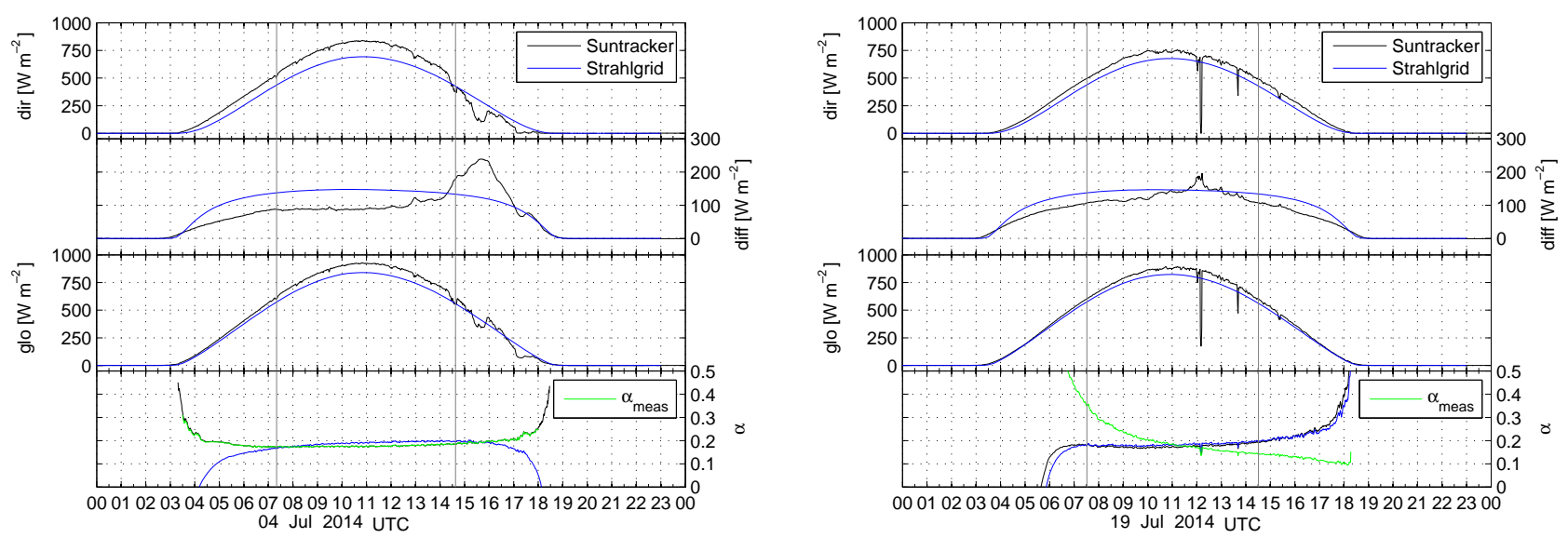

Figure 8. Comparison of the radiation data of the Suntracker and the STRAHLGRID model for the 2 example days at the roof of ZAMG for a horizontally levelled (left) and an inclined pyranometer (right), including the difference of the corrected albedo.
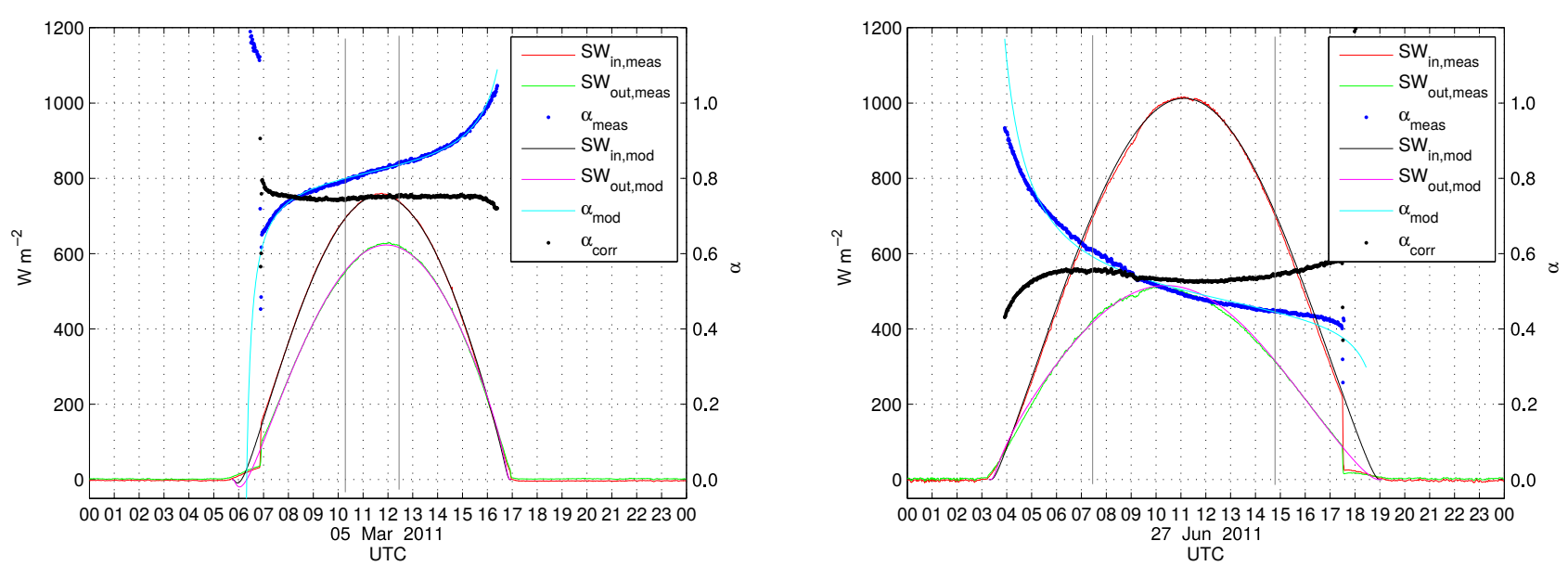

Figure 9. Directly measured (blue dots), modelled (cyan) and corrected (black dots) albedo calculated from data of an inclined pyranometer and a tilted slope at the location of the AWS on Kleinfleißkees on 5 March 2011 (left) and Goldbergkees on 27 June 2011 (right).

which underestimates the known ranges of $V \simeq 0.98$ (Corripio, 2002), caused by model errors.

\subsubsection{Solar radiation model}

If there is no reference measurement nearby, a solar radiation model such as STRAHLGRID can be used. The benefit of the use of a radiation model is that it can be used for every grid point provided for which data on AOD and integral water vapour are available. The results of $\varepsilon$ and $V$ show values within similar ranges, shown in Tables 2 and 3.

As can be seen in Fig. 8 the STRAHLGRID model overestimates the AOD leading to different albedo values. The mean bias error and the mean absolute error for measured and corrected albedo values of both correction procedures, the reference measurement (Suntracker) and the STRAHLGRID model are shown in Table 4.

\subsection{Roof of ZAMG}

To demonstrate the performance of the albedo correction method and its validity also for large inclinations, the pyranometer was horizontally levelled on 4 July 2014 and intentionally inclined with $\sigma_{\mathrm{p}} \approx 25^{\circ}$ in westerly direction with $\left(\gamma_{\mathrm{p}} \approx 270^{\circ}\right)$ on 19 July 2014 over a horizontal concrete plane.

The differences between measured and corrected albedo values are shown in Fig. 2 and Table 2. In Fig. 2 (left) the fitted and measured data show an almost constant diurnal albedo on 4 July 2014, where the pyranometer was horizontally levelled. The anomalies shortly after sunrise and before sunset occur due to the cosine error of the up-facing sensor at large SZA and are outside the SZA ranges of $\vartheta_{\mathrm{s}}<50^{\circ}$ that are used for the correction model.

Figure 2 (right) shows that with an inclined pyranometer the incoming and reflected radiation change unequally, resulting in a modified, wrong surface albedo that is not con- 

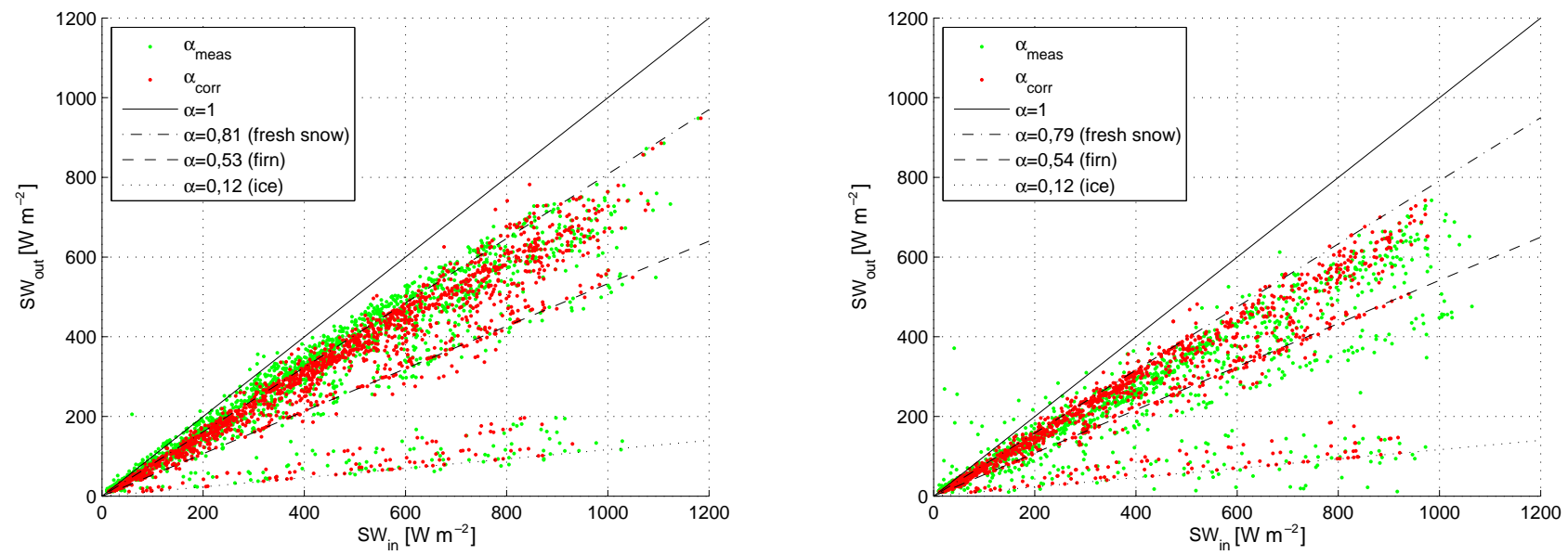

Figure 10. Measured (green) and corrected (red) albedo values on Kleinfleißkees (left) and Goldbergkees (right) for the years 2011 and 2012.
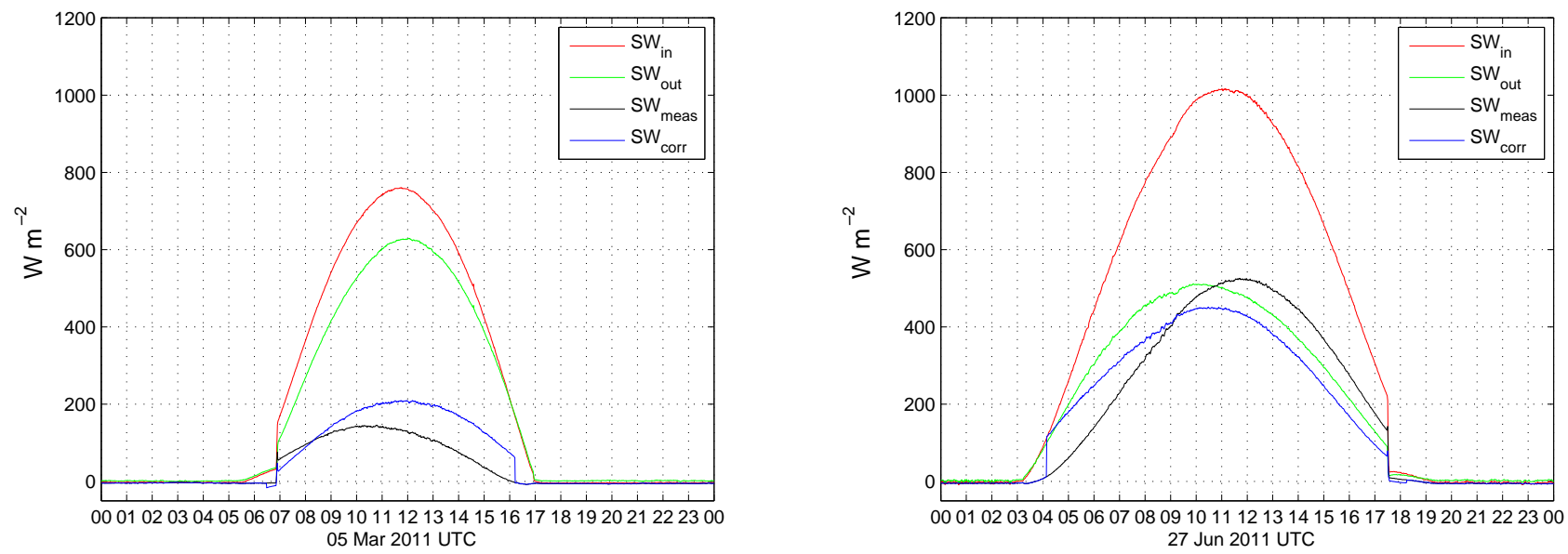

Figure 11. Measured ( $\left.\mathrm{SW}_{\text {meas }}\right)$ and corrected $\left(\mathrm{SW}_{\mathrm{corr}}\right)$ net short-wave radiative balance on Kleinfleißkees on $5 \mathrm{March} 2011$ (left) and on Goldbergkees on 27 June 2011 (right).

stant anymore during 1 clear-sky day. After sunrise, the reflected radiation is higher than the incoming radiation, which is the result of the westerly inclination of the sensor because the down-facing sensor also receives direct incoming radiation due to the flat zenith angle after sunrise. Even within the taken SZA limits of $\vartheta_{\mathrm{s}}<50^{\circ}$ the measured albedo shows a diurnal variation, which has to be corrected.

In both cases it is apparent that the model of both the horizontal and the inclined sensor fits the measured data and the corrected albedo values are within the same ranges.

The accuracy of the correction method can be demonstrated by comparing the measured albedo $\alpha_{\text {meas }}$ as of 4 July 2014 (horizontally levelled sensors) with the corrected albedo $\alpha_{\text {corr }}$ as of 19 July 2014 (tilted sensors) in Table 2 . The deviation between these two results is less than $1 \%$, whereas the deviation between the measured albedo $\alpha_{\text {meas }}$ for both days is $\approx 16 \%$.
As shown in Fig. 8, the corrected albedo with the STRAHLGRID model is $\approx 1 \%$ higher than with the data of the Suntracker. Though the deviations between the $2 \mathrm{ob}$ served days are within the same ranges of $1 \%$ for the corrected albedo and $\approx 16 \%$ for the measured albedo.

\subsection{AWS on Sonnblick glaciers}

In Figs. 2 and 9 it is apparent that the model can be fitted to the measured data for highly inclined and differently directed sensors and slopes. As the figures show, the model differs from the measured values by $\approx 1 \%$ for a SZA of $\vartheta_{\mathrm{s}}<50^{\circ}$. The daily mean albedo within a SZA of $\vartheta_{\mathrm{s}}<50^{\circ}$ is marked by the grey vertical lines.

The correction for a clear day in March is demonstrated for the southwesterly directed Kleinfleißkees where the corrected diurnal mean albedo is 0.11 less than the measured one, even when the period of correction within a SZA of 
Table 4. Mean bias error (MBE) and mean absolute error (MAE) for corrected albedo values between modelled and measured data determined with reference measurement (Suntracker) and solar radiation model (STRAHLGRID).

\begin{tabular}{llllll}
\hline & & \multicolumn{2}{c}{ Suntracker } & \multicolumn{2}{c}{ STRAHLGRID } \\
& & MBE & MAE & MBE & MAE \\
\hline 5 Mar 2011 & FLK & -0.08 & 2.44 & -3.30 & 3.55 \\
27 Jun 2011 & GOK & 0.25 & 1.86 & -1.87 & 2.50 \\
4 Jul 2014 & WHW & 1.51 & 3.55 & 4.07 & 6.52 \\
19 Jul 2014 & WHW & 2.88 & 6.29 & 3.64 & 6.32 \\
\hline
\end{tabular}

$\vartheta_{\mathrm{s}}<50^{\circ}$ is very small in this season due to astronomical reasons.

In contrast, the correction for a clear day in June is demonstrated for the northeasterly directed Goldbergkees where the corrected diurnal mean albedo is 0.03 higher than the measured one (see Fig. 9 and Table 3). The actual tilts and directions were directly measured repeatedly when the sensors were maintained during field works every 1 to 2 months and matched well with the determined results. The results of the AWS on the Sonnblick glaciers were also verified with the method of Mannstein (1985) and lead to the same values.

These results lead to the conclusion that it depends on the direction of the slope and the sensor whether the true value of the diurnal mean albedo is over- or underestimated, demonstrated in Fig. 10, where measured and corrected albedo values for clear-sky days on FLK and GOK in the observed time period are presented.

Furthermore, the absolute value of over- or underestimations in summer months are smaller than in winter months due to generally lower SZA.

\subsection{Short-wave radiative balance}

As shown in the previous sections, the measured albedo differs from the corrected albedo. This means that the amount of short-wave radiation absorbed by the glacier varies likewise. For example, using data from Table 3, directly measured values for Kleinfleißkees indicate that $14 \%$ of the incoming short-wave radiation $\mathrm{SW}_{\text {in }}$ are absorbed by the glacier. In contrast, the corrected values show that $25 \%$ of the incoming short-wave radiation are absorbed during those days.

The correction of the radiative balance using Eq. (26) is demonstrated in Fig. 11 for the 2 sample days, where on 5 March 2011 on Kleinfleißkees the corrected radiative balance $\mathrm{SW}_{\text {corr }}$ is roughly $55 \%$ higher than the measured one $\mathrm{SW}_{\text {meas }}$ and on 27 June 2011 on Goldbergkees $\mathrm{SW}_{\text {corr }}$ is roughly $7 \%$ smaller than $\mathrm{SW}_{\text {meas }}$.

An average over the years 2011 and 2012 the corrected radiative balance $\mathrm{SW}_{\text {corr }}$ on Kleinfleißkees is roughly $8 \%$ higher than the measured one ( $\left.\mathrm{SW}_{\text {meas }}\right)$. On Goldbergkees the corrected radiative balance $\mathrm{SW}_{\text {corr }}$ is roughly $6 \%$ smaller than the measured one. These relatively small absolute values of the relative corrections result from the fact that there are more cloudy than clear-sky days over the year at those locations.

\section{Discussion}

The atmospheric parameters of the albedo correction model consist of two single numbers ( $\varepsilon$ and $V$ ), which does not allow us to account for eventual diurnal variations of the clearsky transmittances. However, the fitting of the albedo correction model to measured or modelled clear-sky reference data in order to derive those bulk atmospheric parameters revealed a small SD and diurnal variation of the residuals at both sites, Sonnblick and Vienna, for all selected and presented days. We attribute this to generally low AOD and water vapour values at the remote and high elevated site Sonnblick, which has been noted in previous studies already (e.g. Weihs et al., 1999). For the urban test site in Vienna, AOD values were especially low during the selected days and showed little diurnal variation as given by a low SD of direct normal irradiance measured with the Suntracker during those days. We also note that calculated values of $V$ (ratio of spectral range) are too low compared to radiative transfer model experiments carried out by Corripio (2002). We explain this by the fact that other errors of the fitting procedure are also lumped into this coefficient. For the correction model we further assumed a constant ratio of diffuse to global radiation $p_{\text {diff }} \simeq 10 \%$. This number is based on data analysis of multiple clear-sky days during different seasons at stations, Sonnblick and Vienna, and is also strengthened by the results of the STRAHLGRID model which gives a similar number.

The described method can be applied on days with a minimum of $2-3 \mathrm{~h}$ of nearly clear-sky conditions. The latter conditions are satisfied for at least $60 \%$ of the days per year on average in high elevated areas in Austria (Hiebl et al., 2011). Although this might imply a limitation of the method for other regions in the world with less sunshine, highest daily sums of melt energy for snow and ice are generally strongly correlated with direct solar radiation and thus low cloudiness. In other words, the correction method is applicable when most melt energy is available and corrections are most needed, independent of the local climate.

We introduced a SZA limit of $\vartheta_{\mathrm{s}}<50^{\circ}$ for the albedo correction method as it assumes a diurnal constant albedo which 
is reasonable only for this SZA range. Due to astronomical reasons, in the Sonnblick region this condition can only be satisfied in the period from mid-March to mid-September as minimum daily SZA values do not fall below this value outside of this period. Again, we do not see this as a major shortcoming of our method, as main melt energy is available within the time between March and September. Future work will investigate whether the diurnal variation of albedo outside of this period has significant implications for the applicability of our method.

The tilts of both the sensors and the slope are also assumed to be constant over 1 day. From field observations and residual analysis of the correction model this assumption appears justified. Under seldom conditions of extreme sensor tilt $\sigma_{\mathrm{p}}>25^{\circ}$ the down-facing sensor can receive parts of the incoming radiation which makes it difficult to separate incoming from reflected radiation. In those rare situations the correction model obviously does not work.

A further improvement of our method would be to directly use a solar radiation model instead of fitting the atmospheric parameters of the albedo correction model to a reference measurement or model. To be successful this would require (i) more accurate AOD data than those used from MODIS satellite here, which is a problem that is still under debate (e.g. Ruiz-Arias et al., 2013; Gueymard, 2012), and (ii) the integration of an automated clear-sky detection algorithm, which is available from e.g. Marty and Philipona (2000) and requires records of long-wave incoming radiation.

Future work will include more in-depth validations of our methodology in the eastern European Alps. Therefore, records of snow/ice depth changes and surface temperatures in connection with energy balance calculations could be very helpful to further test our method. Finally, it is clear that our method needs further testing and validation especially in distinct climates around the world (e.g. tropical glaciers vs. arctic climate).

\section{Conclusions}

Automatically measured snow or ice albedo values in complex terrain on days with low cloudiness are often incorrect due to tilted radiation sensors or the underlying terrain slope. This leads to the conclusion that albedo has to be corrected during those days.
The presented albedo correction method calculates tilts and aspects of sensors and the underlying terrain slope during periods of clear sky. Atmospheric parameters of the correction model are determined using data from a nearby Suntracker as reference measurement with a horizontally levelled pyranometer. In case no nearby radiation reference measurement exists, a solar radiation model can be used to determine these atmospheric parameters. The results show that the solar radiation model is accurate enough for the correction method to be successful. With the determined atmospheric parameters, the model is fitted to the measured data. The results of these fitting procedures are the tilts and aspects of both the sensors and the slopes. With these tilts and directions, the true albedo can be derived from the measured one.

To validate our method, an experimental measurement was setup on a horizontal concrete surface to show that even a constant albedo shows strong artificial diurnal variations and a wrong daily average value when the sensor is inclined, which has to be corrected to get physically correct values.

For the case of the AWSs on two glaciers, the method showed large albedo corrections leading to radiative balances that are up to $55 \%$ higher or lower compared to the (wrongly) measured value for single days. On average over 2 years the correction factors of the radiative balance ranged on the order of 6 to $8 \%$. These results indicate that albedo corrections are strongly needed in order to correctly quantify the energy balance, especially in cases of AWSs in remote locations. Our method is a first step towards such a correction and is easily reproducible and transferable in space. Future applications of our method could involve validations in different climate regions in the world (e.g. tropical glaciers, Arctic or the Himalayan regions) where a lot of glacier mass balance measurements are carried out and the accuracy of the determination of available melt energy is of very high importance. 
Appendix A: Used symbols

\begin{tabular}{|c|c|c|}
\hline$[C]$ & constant factor & [1] \\
\hline$[d]$ & optical path length in the atmosphere & {$[\mathrm{m}]$} \\
\hline$[F]$ & irradiance & {$\left[\mathrm{Wm}^{-2}\right]$} \\
\hline$\left[F_{\text {diff }}\right]$ & diffuse part of irradiance & {$\left[\mathrm{Wm}^{-2}\right]$} \\
\hline$\left[F_{\mathrm{dir}}\right]$ & direct part of irradiance & {$\left[\mathrm{Wm}^{-2}\right]$} \\
\hline$\left[F^{\downarrow}\right]$ & measured incoming irradiance of up-facing pyranometer & {$\left[\mathrm{Wm}^{-2}\right]$} \\
\hline$\left[\boldsymbol{F}^{\downarrow}\right]$ & vector of direct incoming irradiance & {$\left[\mathrm{Wm}^{-2}\right]$} \\
\hline$\left[F^{\uparrow}\right]$ & measured incoming irradiance of down-facing pyranometer & {$\left[\mathrm{Wm}^{-2}\right]$} \\
\hline$\left[F_{\text {hor }}\right]$ & near-surface incoming direct solar irradiance on a horizontal plane & {$\left[\mathrm{Wm}^{-2}\right]$} \\
\hline$\left[F_{\mathrm{pyr}}\right]$ & incoming irradiance on up-facing pyranometer & {$\left[\mathrm{Wm}^{-2}\right]$} \\
\hline$\left[F_{\text {tilt }}\right]$ & incoming irradiance on a tilted plane & {$\left[\mathrm{Wm}^{-2}\right]$} \\
\hline$\left[F_{\mathrm{tilt}}^{\mathrm{dir}}\right]$ & direct part of incoming irradiance on a tilted plane & {$\left[\mathrm{Wm}^{-2}\right]$} \\
\hline$[I]$ & intensity of near-surface global incident solar radiation & {$\left[\mathrm{Wm}^{-2}\right]$} \\
\hline$\left[I_{0}\right]$ & intensity of TOA incident solar radiation & {$\left[\mathrm{Wm}^{-2}\right]$} \\
\hline$[n]$ & normal unit vector & {$[1]$} \\
\hline$\left[p_{\text {diff }}\right]$ & diffuse part of global radiation & [\%] \\
\hline$\left[p_{\text {dir }}\right]$ & direct part of global radiation & {$[\%]$} \\
\hline$[r]$ & actual sun-earth distance & {$[\mathrm{m}]$} \\
\hline$[\bar{r}]$ & mean sun-earth distance & [m] \\
\hline$[\tilde{r}]$ & ratio of $r / \bar{r}$ & [1] \\
\hline$[S]$ & solar constant $\left(1367 \mathrm{Wm}^{-2}\right)$ & {$\left[\mathrm{Wm}^{-2}\right]$} \\
\hline$\left[S_{\text {terr }}\right]$ & near-surface direct solar radiation & {$\left[\mathrm{Wm}^{-2}\right]$} \\
\hline$[\mathrm{SW}]$ & $\begin{array}{l}\text { general global radiative balance (measured, modelled or corrected) with } \\
\mathrm{SW}_{\mathrm{in} / \mathrm{mod} / \text { corr }}+\mathrm{SW}_{\text {out }} \text { mod }\end{array}$ & {$\left[\mathrm{Wm}^{-2}\right]$} \\
\hline$\left[\mathrm{SW}_{\text {corr }}\right]$ & with corrected values calculated global radiative balance $\mathrm{SW}_{\text {in,corr }}+\mathrm{SW}_{\text {out }}$ & {$\left[\mathrm{Wm}^{-2}\right]$} \\
\hline$\left[\mathrm{SW}_{\mathrm{in}}\right]$ & incoming measured short-wave radiation & {$\left[\mathrm{Wm}^{-2}\right]$} \\
\hline$\left[\mathrm{SW}_{\text {meas }}\right]$ & with measured data calculated global radiative balance with $\mathrm{SW}_{\mathrm{in}}+\mathrm{SW}_{\text {out }}$ & {$\left[\mathrm{Wm}^{-2}\right]$} \\
\hline$\left[\mathrm{SW}_{\text {out }}\right]$ & reflected measured short-wave radiation (negative sign) & {$\left[\mathrm{Wm}^{-2}\right]$} \\
\hline$[T]$ & temperature & {$\left[{ }^{\circ} \mathrm{C}\right]$} \\
\hline$[t]$ & time & {$[\mathrm{s}]$} \\
\hline$[V]$ & ratio between spectral range of pyranometer and TOA irradiance & [1] \\
\hline$\left[V_{\text {mod }}\right]$ & $\begin{array}{l}\text { ratio between spectral range of pyranometer and TOA irradiance, determined } \\
\text { with solar radiation model }\end{array}$ & [1] \\
\hline$[\alpha]$ & general name of albedo & [1] \\
\hline$\left[\alpha_{\text {concrete }}\right]$ & albedo of concrete & [1] \\
\hline$\left[\alpha_{\text {corr }}\right]$ & corrected albedo & [1] \\
\hline$\left[\alpha_{\text {meas }}\right]$ & with measured data direct calculated albedo & {$[1]$} \\
\hline$\left[\alpha_{\bmod }\right]$ & modelled albedo & [1] \\
\hline$\left[\alpha_{\text {true }}\right]$ & true albedo & [1] \\
\hline$[\gamma]$ & direction of a tilted plane $\left(\right.$ north $=0^{\circ}$ ) & {$\left[{ }^{\circ}\right]$} \\
\hline$\left[\gamma_{\mathrm{p}}\right]$ & direction of pyranometer $\left(\right.$ north $\left.=0^{\circ}\right)$ & {$\left[{ }^{\circ}\right]$} \\
\hline$\left[\gamma_{t}\right]$ & direction of tilted slope $\left(\right.$ north $\left.=0^{\circ}\right)$ & {$\left[{ }^{\circ}\right]$} \\
\hline$[\varepsilon]$ & extinction coefficient & {$\left[\mathrm{m}^{-1}\right]$} \\
\hline$\left[\varepsilon_{\mathrm{mod}}\right]$ & extinction coefficient, determined with solar radiation model & {$\left[\mathrm{m}^{-1}\right]$} \\
\hline$[\widetilde{\varepsilon}]$ & extinction coefficient & {$\left[\mathrm{m}^{-1}\right]$} \\
\hline$[\theta]$ & longitude & {$\left[{ }^{\circ}\right]$} \\
\hline$\left[\vartheta_{\mathrm{p}}\right]$ & $\begin{array}{l}\text { angle between normal vector to the tilted pyranometer and vector of incoming } \\
\text { direct irradiance }\end{array}$ & {$\left[{ }^{\circ}\right]$} \\
\hline$\left[\vartheta_{\mathrm{s}}\right]$ & solar zenith angle (SZA) & {$\left[{ }^{\circ}\right]$} \\
\hline$\left[\vartheta_{\mathrm{t}}\right]$ & $\begin{array}{l}\text { angle between normal vector to the tilted slope and vector of incoming direct } \\
\text { irradiance (specific definition) }\end{array}$ & {$\left[{ }^{\circ}\right]$} \\
\hline$\left[\vartheta_{\text {tilt }}\right]$ & $\begin{array}{l}\text { angle between normal vector to any tilted slope and vector of incoming direct } \\
\text { irradiance (general definition) }\end{array}$ & {$\left[{ }^{\circ}\right]$} \\
\hline$[\sigma]$ & angle of inclination of a tilted plane & {$\left[{ }^{\circ}\right]$} \\
\hline$\left[\sigma_{\mathrm{p}}\right]$ & angle of inclination of the pyranometer & {$\left[{ }^{\circ}\right]$} \\
\hline$\left[\sigma_{t}\right]$ & angle of inclination of the tilted slope & {$\left[{ }^{\circ}\right]$} \\
\hline$[\phi]$ & latitude & {$\left[{ }^{\circ}\right]$} \\
\hline$\left[\varphi_{\mathrm{s}}\right]$ & azimuth of the sun & {$\left[{ }^{\circ}\right]$} \\
\hline$[\omega]$ & solid angle & {$\left[{ }^{\circ}\right]$} \\
\hline
\end{tabular}


Acknowledgements. This work was financed by the FEMtech programme of the Austrian Research Promotion Agency (FFG) and the Central Institute for Meteorology and Geodynamics (ZAMG). The data were gained within a long-term glacier monitoring project, Global Cryosphere Watch Sonnblick Glacier (GCW_S-G), partly financed by the Federal Ministry of Agriculture, Forestry, Environment and Water Management (BMLFUW) and the Austrian radiation monitoring network (ARAD), partly financed by the Federal Ministry of Science, Research and Economy (BMWFW). We thank all referees for their useful comments.

Edited by: A. Klein

\section{References}

Allen, R., Trezza, R., and Tasumi, M.: Analytical integrated functions for daily solar radiation on slopes, University of Idaho Research and Extension Center, United States, Agr. Forest Meteorol., 139.1, 55-73, 2006.

Amsys: Neuartige Neigungssensoren für die präzise Winkelmessung, Die elektronische Wasserwaage, available at: http://www. amsys.de/sheets/amsys.de.aan514_3.pdf (last access: 27 January 2015), 2012.

Brock, B. W., Willis, I. C., and Sharp, M. J.: Measurement and parameterization of albedo variations at Haut Glacier d'Arolla, Switzerland, J. Glaciol., 46, 675-688, 2000.

Brock, B. W.: An analysis of short-term albedo variations at Haut Glacier d'Arolla, Switzerland, Geografiska Annaler, 86A, 53-65, 2004.

Carroll, J. J. and Fitch, B. W.: Effects of solar elevation and cloudiness on snow albedo at the South Pole, J. Geophys. Res., 86, 5271-5276, doi:10.1029/JC086iC06p05271, 1981.

Corripio, J.: Modelling the engergy balance of high altitude glacierised basins in the Central Andes, $\mathrm{PhD}$ thesis, University of Edinburgh, UK, 2002.

Cutler, P. M. and Munro, D. S.: Visible and near-infrared reflectivity during the ablation period on Peyto Glacier, Alberta, Canada, J. Glaciol., 42, 333-340, 1996.

DeWalle, D. R. and Rango, A.: Principles of Snow Hydrology, Cambridge University Press, NY, USA, 2008.

Dirmhirn, I. and Eaton, F.: Some characteristics of the albedo of snow, J. Appl. Meteorol., 14, 375-379, 1975.

Gueymard, C. A.: Temporal variability in direct and global irradiance at various time scales as affected by aerosols, Sol. Energy, 86, 3544-3553, doi:10.1016/j.solener.2012.01.013, 2012.

Haiden, T., Kann, A., Wittmann, C., Pistotnik, G., Bica, B., Gruber, C.: The Integrated Nowcasting through Comprehensive Analysis (INCA) System and its Validation over the Eastern Alpine Region, Weather Forecast., 26/2, 166-183, doi:10.1175/2010WAF2222451.1, 2011.

Hiebl, J., Reisenhofer, S., Auer, I., Böhm, R., Schöner, W.: Multimethodical realisation of Austrian climate maps for 1971-2000, Adv. Sci. Res., 6, 19-26, doi:10.5194/asr-6-19-2011, 2011.

Ineichen, P., Perez, R., and Seals, R.: The importance of correct albedo determination for adequately modeling energy received by tilted surfaces, Sol. Energy, 39, 301-305, doi:10.1016/S0038092X(87)80016-6, 1987.
Jonsell, U., Hock, R., Holmgren, B.: Spatial and temporal variations in albedo on Storglaciären, J. Glaciol., 49, 59-68, 2003.

Kipp \& Zonen: Instruction Manual, CNR4 Net Radiometer, v. 1107, Campbell Scientific, Inc., Kipp \& Zonen B. V., AM Delft, The Netherlands, 2010.

Konzelmann, T. and Ohmura, A.: Radiative fluxes and their impact on the energy balance of the Greenland ice sheet, J. Glaciol., 41, 490-502, 1995.

Landry, C., Painter, T., Barrett, A., and Cassidy, M.: Toward standardization in Methods and Techniques for Measuring and Monitoring Snowcover Albedo, 10 December 2007, San Francisco, CA, USA, American Geophysical Union, Fall Meeting 2007, abstract no. \#GC32A-03, 2007.

Liljequist, G. H.:Energy exchange of an Antarctic snow field: Shortwave radiation (Maudheim $71^{\circ} 03^{\prime} S, 10^{\circ} 56^{\prime} W$ ), in NorwegianBritish-Swedish Antarctic Expedition, 1949-1952, Scientific Results, 2, 1A, Norsk Polarinstitutt, Oslo, 1956.

Mannstein, H.: The interpretation of albedo measurements on a snow covered slope, Arch. Met. Geoph. Biocl., Ser. B., 36, 73$81,1985$.

Marty, C. and Philipona, R.: The clear-sky index to separate clearsky from cloudy-sky situations in climatic research, Geophys Res. Lett., 27, 2649-2652, doi:10.1029/2000GL011743, 2000.

Meinander, O., Wuttke, S. Seckmeyer, G., Kazadzis, S., Lindfors, A., Kyrö, E.: Solar Zenith Angle Asymmetry Cases in Polar Snow UV Albedo, Geophysica, 45, 183-198, 2009.

Mellor, M.: Engineering properties of snow, J. Glaciol., 19, 15-65, 1977.

Muneer, T.: Solar Radiation and Daylight Models, 2nd Edn., Elsevier Butterworth-Heinemann, Oxford, 1997.

Oerlemans, J. and Knap, W. H.: A 1 year record of global radiation and albedo in the ablation zone of Morteratschgletscher, Switzerland, J. Glaciol., 44, 231-238, 1998.

Oerlemans, J.: The Microclimate of Valley Glaciers, Igitur, Utrecht University, the Netherlands, 138 pp., 2010.

Olefs, M. and Schöner W.: A new solar radiation model for research and applications in Austria, EGU General Assembly, 14, EGU2012-9705, 2012.

Olefs, M., Schöner W., Suklitsch, M., Wittmann, C., Niedermoser, B., Neururer, A., and Wurzer, A.: SNOWGRID - A new operational snow cover model in Austria, International Snow Science Workshop Grenoble - Chamonix Mont-Blanc, 2013.

Olefs, M., Baumgartner, D. J., Obleitner, F., Bichler, C., Foelsche, U., Pietsch, H., Rieder, H. E., Weihs, P., Geyer, F., Haiden, T., and Schöner, W.: The Austrian radiation monitoring network ARAD - best practice and added value, Atmos. Meas. Tech. Discuss., 8, 10663-10710, doi:10.5194/amtd-8-10663-2015, 2015.

Paterson, W. S. B.: The physics of glaciers, 3 ed., ButterworthHeinemann, Oxford, 481 pp., 1994.

Pellicciotti, F. Brock, B., Strasser, U., Burlando, P., Funk, M., Corripio, J.: An enhanced temperature-index glacier melt model including the shortwave radiation balance: development and testing for Haut Glacier d'Arolla, Switzerland, J. Glaciol., 51, 573-287, 2005.

Pirazzini, R.: Surface albedo measurements over Antarctic sites in summer, J. Geophys. Res., 109, D20118, doi:10.1029/2004JD004617, 2004.

Reda, I. and Andreas, A.: Solar position algorithm for solar radiation applications, National Renewable Energy Laboratory 
(NREL), Golden, CO, USA, Technical Rep. NREL/TP-56034302, 56 pp., 2008.

Rontu Carlon, N., Papanastasiou, D. K., Fleming, E. L., Jackman, C. H., Newman, P. A., and Burkholder, J. B.: UV absorption cross sections of nitrous oxide $\left(\mathrm{N}_{2} \mathrm{O}\right)$ and carbon tetrachloride $\left(\mathrm{CCl}_{4}\right)$ between 210 and $350 \mathrm{~K}$ and the atmospheric implications, Atmos. Chem. Phys., 10, 6137-6149, doi:10.5194/acp-10-61372010, 2010.

Röthlisberger, H., and Lang, H.:Glacial hydrology, in: Glacio Fluvial Sediment Transfer, edited by: Gurnell, A. M., Clark, M. J., Wiley, Chichester, 207-284, 1987.

Ruiz-Arias, J. A., Dudhia, J., Gueymard, C. A., and Pozo-Vázquez, D.: Assessment of the Level-3 MODIS daily aerosol optical depth in the context of surface solar radiation and numerical weather modeling, Atmos. Chem. Phys., 13, 675-692, doi:10.5194/acp-13-675-2013, 2013.

Santamouris, M.: Environmental Design of Urban Buildings: an Integrated Approach, Earthscan, UK, 2006.

Schaaf, C., Li, X., and Strahler, A.: Topographic effects on bidirectional and hemispherical reflectances calculated with a geometric-optical canopy model, IEEE T. Geosci. Remote, 32, 1186-1193, 1994.
Sicart, J., Ribstein, P., Wagnon, P., and Braunstein, D.: Clear-sky albedo measurements on a sloping glacier surface: A case study in the Bolivian Andes, J. Geophys. Res., 106, 31729-31737, doi:10.1029/2000JD000153, 2001.

Wang, X. and Zender, C.: MODIS snow albedo bias at high solar zenith angle relative to theory and to in situ observations in Greenland, Remote Sens. Environ., 114, 563-575, doi:10.1016/j.rse.2009.10.014., 2010.

Warren, S.: Optical properties of snow, Rev. Geophys., 20, 67-89, doi:10.1029/RG020i001p00067, 1982.

Warren, S. and Wiscombe, W.: A Model for the Spectral Albedo of Snow. II: Snow Containing Atmospheric Aerosols, J. Atmos. Sci., 37, 2734-2745, 1980.

Weihs, P., Simic, S., Laube, W., Mikiekewicz, W., and Rengarajan, G.: Albedo Influences on Surface UV Irradiance at the Sonnblick High-Mountain Observatory (3106 m Altitude), J. Appl. Meteorol., 38, 1599-1610, 1999.

Weiser, U.: Methode zur Korrektur von Neigungsfehlern bei der zeitlichen Albedo-Messung an wolkenlosen Tagen, MSc thesis, University of Vienna, Vienna, Austria, 2012.

Wiscombe, W. and Warren, S.: A Model for the Spectral Albedo of Snow. I: Pure Snow, J. Atmos. Sci., 37, 2712-2733, 1980. 